\title{
MOGUĆNOSTI PODSTICANJA KREATIVNOSTI UČENIKA ${ }^{1}$
}

APSTRAKT: Polazeći od činjenice da je kreativnost važan deo celovite ličnosti, cilj ovog rada jeste pregled mogućih oblika njenog podsticanja u radu sa učenicima. Cilj se ostvaruje primenom metode teorijske analize, uz primenu tehnike analize sadržaja. U radu se polazi od različitih definicija kreativnosti, te bližeg određenja karakteristika kreativnih pojedinaca. Drugi deo rada odnosi se na razmatranje uloge nastavnika u procesu razvoja kreativnosti kroz sledeća pitanja: da li je kreativan nastavnik preduslov za razvoj kreativnosti kod učenika i da li u nastavi kreativnost podstičemo ili je gušimo? Rezultati analize nalaza relevantnih istraživanja i proučavane literature upućuju na određeni broj razrađenih strategija u okviru nastave, vannastavnih i vanškolskih aktivnosti, koji su predstavljeni u radu. U zaključnim razmatranjima predstavljene su pedagoške implikacije proučavanja date problematike.

Ključne reči: podsticanje, kreativnost, nastavnik, nastava, učenici.

\section{POSSIBILITIES FOR ENCOURAGING STUDENTS' CREATIVITY}

ABSTRACT: Starting from the fact that creativity is an important part of overall personality, the aim of this paper is to review possible forms of encouraging it in work with students. The goal is achieved using the method of theoretical analysis and the content analysis technique. The paper starts from various definition of creativity and a closer determination of the characteristics of creative individuals. The second part deals with the consideration of the role of teachers in the process of developing creativity through the following questions: is a creative teacher a prerequisite for the development of students' creativity, and are we encouraging or reducing creativity in teaching process? The results of the analysis of the findings of relevant research and the study literature refer to a number of elaborated strategies in the context of the teaching process and extracurricular activities, which are presented in the paper. In the concluding observations pedagogical implications of the study of the given problem are presented.

Key words: encouragement, creativity, teacher, teaching, creativity, students.

\footnotetext{
${ }^{1}$ Rad je nastao u okviru projekta „Kvalitet obrazovnog sistema Srbije u evropskoj perspektivi” (KOSSEP), br. 179010, koji finansira Ministarstvo prosvete, nauke i tehnološkog razvoja Republike Srbije.
} 


\section{UVOD}

Kreativnost ima značajno mesto u čovekovom životu jer ga čini plemenitijim i bogatijim. Stvaralaštvo i kreativnost postali su imperativ savremenog društva (Bačlija-Sušić i Sućeska-Ligutić 2017: 74). Moderna vremena zahtevaju kreativne osobe koje su u stanju da odgovore na sve složenije zahteve koje društvo postavlja (Perić 2013: 149). Darovitost, talenti i kreativnost predstavljaju visoko vrednovana svojstva savremenog čoveka i napretka društva, što ih čini visoko poželjnim ciljevima obrazovanja i zadacima savremene škole (Fudurić 2012: 115; Maksić 2015: 11). Kreativnost u nastavi podstiče radoznalost, upornost, moć zapažanja, formiranje vlastitih misli, razvijanje inicijative, samostalnosti, te formiranje čoveka i njegovog duha (Zuliani, Matić i Keteleš 2012: 25). Stvaralaštvo i kreativnost su bitni faktori razvoja emocionalnih, intelektualnih i socijalnih snaga čovekove ličnosti, doprinoseći njenom svestranom i harmoničnom razvoju. Ranije se smatralo da samo određeni pojedinci poseduju kreativne potencijale, dok se danas zna da je kreativnost sadržana u porama svake ličnosti, a da do njenog ispoljavanja dolazi u zavisnosti od podsticaja sredine $\mathrm{u}$ kojoj osoba živi. Nažalost, praksa pokazuje da naša sredina ne pruža dovoljno podsticaja za razvoj kreativnosti dece i mladih. U ovaj proces neophodno je uključiti sve učesnike vaspitno-obrazovnog procesa, porodicu, kao i širu društvenu zajednicu. Učesnici vaspitno-obrazovnog procesa treba da posluže kao dobar model svojim učenicima, da i sami razviju kreativne tehnike i metode rada, da se usavršavaju i uključuju u celoživotno obrazovanje, kako bi mogli ići u korak sa vremenom i podsticati kreativnost na efikasan način.

\section{DEFINISANJE KREATIVNOSTI}

Kreativnost nije jednoznačna pojava koja se može precizno definisati, već je, s obzirom na svoju prirodu, kompleksna i višestrana (Simel i Gazibara 2013: 189). Kreativnost je, dakle:

„kompleksan fenomen, složena sposobnost ličnosti sastavljena od brojnih činilaca koji podstiču i podržavaju stvaralaštvo, kao što su originalnost, fleksibilnost i fluentnost, ali i druge kategorije, među kojima se izdvajaju intelektualni faktori (mišljenje, mašta, pamćenje), faktori sposobnosti i neintelektualni faktori (motivacija, tolerantnost, svojstva karaktera, aspiracija i sl.)" (Đorđević 2014: 43).

Stvaralački proces definisan je kao proces povezivanja ranije nepovezanih stvari. Jedan od prvih načina njegovog definisanja ukazuje na to da je stvaralački proces zapravo ,promišljen proces stvaranja novih kombinacija ili modelovanja 
građe, pokreta, reči, simbola ili ideja i omogućavanje da proizvod bude na određen način dostupan drugima, vizuelno ili drugačije" (Maj1 1968: 6).

Kreativnost se u literaturi sve češće definiše kao stvaranje novog, što je rezultat rada divergentnog procesa mišljenja ili trenutnog inspiracijskog procesa, oba procesa su oblici ponašanja ličnosti koji se u osnovi moraju razvijati učenjem (Balažević 2010: 181). Kreativnost se opisuje kao sposobnost da se stvore proizvodi koji su novi, neočekivani, inovativni i originalni, koji su istovremeno i prikladni, odnosno odgovaraju na zahteve i ograničenja određenog zadatka (Kaufman \& Baer 2004: 2, prema: Bodroža, Maksić i Pavlović 2013: 109). Kreativnost se, takođe, definiše i preko odlika pojedinca koji stvara, odnosno preko njegovih sposobnosti, karakteristika i kognitivnih procesa koji ga vode ka novim i prikladnim idejama (Diakidoy \& Phitaka 2002, prema: Bodroža, Maksić i Pavlović 2013: 109).

\subsection{Karakteristike kreativnih učenika}

Psiholog Gilford ljudsko mišljenje deli na konvergentno i divergentno, prepoznajući ovo drugo kao osnovnu karakteristiku kreativnosti. Tako, ovaj autor ističe nekoliko činilaca divergentnog mišljenja: fleksibilnost (sposobnost proizvodnje relevantnih ideja), fluentnost (sposobnost simultanog sagledavanja različitih mogućnosti), originalnost (sposobnost proizvodnje retkih i/ili novih ideja) i elaborativnost (sposobnost ukrašavanja ideja detaljima). Pored navedenih, od važnosti su i činioci koji nisu svrstani među divergentne, a to su: osetljivost za probleme (sposobnost uočavanja nedostataka) i redefinicija (sposobnost napuštanja starih načina tumačenja poznatih predmeta kako bi se koristili u nove svrhe) (Guilford 1968; Torrance 1979; Goff \& Torrance 2000, prema: Jukić 2010: 293).

Kreativne stvaraoce odlikuje otvorenost uma, sposobnost da prihvate neizvesnost i složenost egzistencije, pojmovna jednostavnost životnih problema i tolerancija na greške. Oni, takođe, poseduju smisao za humor, emocionalnu stabilnost, naklonost ka apstraktnom mišljenju, poverenje u sopstveni rad i spremnost za rizik. Kreativne stvaraoce karakteriše motivisanost opštim i ličnim interesima, divergentno i konvergentno mišljenje, opuštenost i pažnja, emocionalni angažman i emocionalna distanciranost. Kreativni pojedinci umereno preduzimaju rizik, imaju želju za nadilaženjem teškoća i veliki poriv ka rešavanju problema (Maksić i Đurišić-Bojanović 2003: 46; Maksić 2006: 36).

Nastavnici često opisuju kreativne učenike kao osobe koje su sklone umetnosti, maštovite, radoznale, nezavisne, inventivne i originalne, sa široko razvijenim interesovanjima, osobe koje umeju da postave prava pitanja i da daju tačne i brze odgovore, kao i osobe visokih intelektualnih sposobnosti (Bodroža, 
Maksić i Pavlović 2013: 110). Profili kreativnih pojedinaca obuhvataju znanja (u oblasti i u vezi sa zadatkom) i karakteristike usmerene na ličnost (stavovi, inteligencija, motivacija). Za okruženje koje podržava razvoj kreativnosti, najvažniji su stavovi nastavnika i nastave strategije koje primenjuju u nastavnom procesu (Pavlović i Maksić 2014: 466).

\section{PODSTICANJE KREATIVNOSTI U RADU SA UČENICIMA}

\subsection{Kreativan nastavnik - preduslov za razvoj kreativnosti kod učenika}

Nastavnik treba da ohrabri učenike da uočavaju probleme i postavljaju pitanja, bez nametanja sopstvenog mišljenja i vlastitih rešenja, treba da bude otvoren za nove mogućnosti koje pružaju učenici (Bognar 2012: 16). Kreativan nastavnik se odlikuje izraženom potrebom za inovacijama, naglašenom zainteresovanošću za predmet koji predaje i za sva dešavanja unutar njegovog kruga uticaja (Ninčević i Jurić 2016: 250).

Elementi koji čine sastavni deo metodičkog stila nastavnika, koji podsticajno deluju na kreativnost, podeljeni su u nekoliko grupa:

1) primena nastavnih strategija, metoda, sredstava, postupaka i oblika koji podstiču kreativnost učenika, istraživanje, kritičko mišljenje, sposobnost odlučivanja, samostalnost $u$ radu, međusobnu komunikaciju (ukrštenice, skrivalice, asocijacije, kvizovi, mape uma, zagonetke, rebusi, igre, audio- i video-zapisi, karikature, skice, mimika, pantomima, modeli, kolaž, crtanje, anegdote, metafore, oluje ideja i sl.);

2) otvorenost prema idejama i inicijativama učenika;

3) poznavanje i primenjivanje pravila uspešne komunikacije;

4) demokratski stil rukovođenja razredom;

5) stvaranje okruženja bliskosti i prijateljstva;

6) pri ocenjivanju preferiranje ipsativnog pristupa merenju postignuća (Jukić 2010: 297).

Poželjno je da nastavnik koristi humor u radu sa učenicima, primeren mestu i situaciji učenja. Humor je usko povezan sa kreativnošću, karakterišu ih logični i apsurdni, neočekivani obrti u razmišljanju. Duhovitost zahteva sposobnost divergentnog mišljenja, naviku uma da se izlazi izvan područja uobičajenog i poznatog, aktivno povezivanje ideja na različite i neočekivane načine. Zato, 
nastavnik i sam mora biti kreativan kako bi mogao da podstiče tu osobinu kod svojih učenika. Još je u 19. veku čuveni pedagog Disterveg ukazao na glavni uzrok školskog neuspeha i definisao ga sledećom rečenicom: , Škola vredi onoliko koliko vredi njen nastavnik". Shodno tome, kreativan nastavnik je osnovni preduslov kvalitetnog i kreativnog vaspitno-obrazovnog procesa, a najkreativniji će biti ukoliko je intrinzično motivisan (Jukić, 2010: 298), jer nastavnik koji želi kreativno da stvara, istovremeno razvija i svoje kompetencije da stvaralački entuzijazam prenese i na učenike (Zrilić i Košta 2009: 170).

\subsection{Kreativnost u nastavi - da li je podstičemo ili gušimo?}

Učitelji i nastavnici često veruju da su samo pojedini učenici kreativni i u ovakvom uverenju se ogleda glavna prepreka u podsticanju kreativnosti u nastavi. Takođe, stroga i formalna nastavna atmosfera ograničava razvoj kreativnosti time što sputava učenike da izražavaju svoje mišljenje i predstavljaju ideje. U ovakvom okruženju učenici će se, u najvećem broju slučajeva, ponašati prema već formiranim uverenjima nastavnika, razvijaće konformističke oblike ponašanja koji su u osnovi u potpunoj suprotnosti sa idejom kreativnosti (Kunac 2015: 442). Kreativnost najviše koči autoritet učitelja, koji i dalje izričito zastupa paradigme tradicionalne škole koje se ogledaju u jednoličnosti i neučinkovitosti (Zrilić i Košta 2009: 162). Sputavanje kreativnosti se može videti u insistiranju na samo jednom ispravnom odgovoru, načinu, metodi, netoleranciji prema učeničkim greškama, ignorisanju učeničkih ideja i novih rešenja (Somolanji i Bognar 2008: 92). Nastavnik, svojim ponašanjem, očekivanjima i postupcima može stvarati kvalitetne uslove za optimalan razvoj učenikovih sposobnosti i umenja, ali ih takođe može obeshrabriti u pronalaženju novih, neobičnih i drugačijih ideja ukoliko ima neadekvatna uverenja, krutost u prilagođavanju nepredviđenim situacijama i zatvorenost pristupa novim metodama poučavanja. Nastavnik mora biti otvoren za nova i originalna rešenja, spreman da prihvati mišljenja učenika koja se razlikuju od uobičajenog (Koludrović i Reić-Ercegovac 2010: 430).

Udžbenici, prvenstveno udžbenici razredne nastave treba da budu prožeti sadržajima koji razvijaju kreativnost učenika, jer oni predstavljaju temelje vrednosti koje će učenici nositi sa sobom tokom života. Rezultati istraživanja (Dubovicki 2012: 215-216) ukazuju na nedovoljno podsticanje kreativnosti kroz udžbenike razredne nastave, posebno kada su u pitanju udžbenici za nastavu Matematike u kojima nedostaju zadaci koji podstiču divergentno mišljenje učenika. S obzirom na prirodu predmeta, uočavaju se brojne mogućnosti osnaživanja i 
jačanja kreativnog mišljenja učenika putem raznovrsnih problemskih zadataka koji se mogu povezati sa svakodnevnim životom učenika.

\section{3. Šta možemo uraditi u okviru nastavnog procesa?}

Stevanović (2003: 189-369) navodi deset modela kreativne nastave koji se mogu primeniti u radu doprinoseći razvoju kreativnog mišljenja učenika, istovremeno razvijajući i usavršavajući kreativne potencijale samih nastavnika:

1) Kreativno-stvaralački modeli - ujedinjuju stvaralaštvo i kreativnost sa ciljem da učenici razviju stvaralačko mišljenje sistematičnim uvođenjem u sadržaje, metode i tehnike stvaralačkog rada. Ovaj model se sastoji od tri podmodela: kreativno čitanje (razmatranje određenih podataka na različite načine), kritičko čitanje (osposobljavanje učenika za prosuđivanje, te izdvajanje najbitnijih sadržaja) i formulisanje naslova (formulisanje glavne ideje/teme teksta).

2) Problemsko-otkrivajući modeli - kroz problemsku nastavu učenik se osposobljava da samostalno, i/ili uz pomoć nastavnikovih uputstava, putem razmišljanja i istraživačkog rada, dolazi do kreativnih rešenja.

3) Recepcijsko-estetički modeli - zasnivaju se na relaciji autora, dela i učenika, uz istraživačke zadatke koji obuhvataju produktivno čitanje (proizvođenje novih ideja), fleksibilno čitanje (brzo čitanje i razumevanje pročitanog), čitanje radi rešavanja problema (identifikovanje problema i pronalaženje rešenja) i čitanje uz komentare (aktivno prosuđivanje delova teksta od strane učenika).

4) Esejističko-sintetički modeli - nastavnik postavlja ključna pitanja i daje uputstva za rad, dok učenici tragaju za odgovorima esejističkog tipa.

5) Algoritamsko-matematički modeli - najkorisniji su u nastavi Matematike, ali imaju primenu i u ostalim predmetima. Učenici mogu i samostalno sastavljati algoritme, što im omogućava veću slobodu prilikom istraživanja.

6) Egzemplarno-paradigmatski modeli - zadatak nastavnika je da objasni učenicima egzemplarne sadržaje, nakon čega učenici samostalno istražuju analogne sadržaje.

7) Multimedijsko-višeizvorni modeli - učenje se odvija uz što više izvora, uz povezivanje gradiva sa filmovima, člancima iz novina i/ili reportažama. 
8) Kompjutersko-simulacijski modeli - učenje uz primenu savremene obrazovne tehnologije. Nastavnik preuzima ulogu organizatora i koordinatora, od čijih ideja zavisi kreativni pristup ovoj tehnologiji. Ovaj model omogućava učenje na daljinu.

9) Književno-umetnički modeli - pogodni su za nastavu jezika, kako maternjeg tako i stranog. Učenici mogu dobiti zadatak da dati tekst svedu na najznačajnije informacije, da analiziraju tekst, ili da mu daju neku novu, sopstvenu dimenziju. Književno-umetnički modeli pružaju brojne mogućnosti za razvoj kreativnosti i stvaralaštva učenika.

10) Strukturalno-grafički modeli - mogu da se koriste za struktuiranje gradiva i upotrebu grafičkih prikaza pri učenju (tablice, crteži, grafikoni, dijagrami).

Smisao savremene nastave nije da učenicima servira gotova znanja koja će oni usvojiti i reprodukovati, već da motiviše učenike da preuzmu ulogu aktivnog učesnika u nastavnom procesu (Laketa 2015: 330). Istraživanja su pokazala da učenici koji su na kreativan način uključeni u nastavu mogu da usvoje od 70\% do 90\% školskog gradiva (Portner-Pavićević, Večei-Funda i Janjušević 2014: 79). Uloga škole i nastavnika, kada je kreativnost u pitanju, sastoji se u prepoznavanju oblasti kroz koju će se talenat i sposobnosti ispoljiti, sticanju osnovnih znanja i ovladavanju izabranim poljem, kao i u razvoju učeničke motivacije da istraje $u$ radu. Kada je reč o ulozi samog nastavnika, njegov zadatak je da stvori otvoreno, fleksibilno i nekonvencionalno okruženje usmereno na učenika, u kome se podstiče razvoj osobina ličnosti, stilova mišljenja, znanja i veština potrebnih za kreativno mišljenje. Ohrabrivanje, sloboda i dozvola da se preuzimaju rizici stvaraju pozitivnu atmosferu, kao i osećaj sigurnosti u kojoj će učenici imati slobodu da ispolje vlastitu kreativnost. Rezultati istraživanja (Bodroža, Maksić i Pavlović 2013: 120-122) ukazuju na to da nastavnici najčešće vide mogućnosti za podsticanje kreativnosti, u okviru škole, u stvaranju podsticajne školske klime, kroz ohrabrivanje, nagrađivanje i uvažavanje. Tako, ohrabrivanje se odnosi na stvaranje klime tolerancije i slobode mišljenja, koje će pružiti učenicima mogućnost da se osećaju slobodnim da isprobaju, a zatim ponude različite načine rešavanja problema, da neguju kritičko mišljenje i samostalnost. Dalje, nagrađivanje se ogleda $u$ davanju podrške i javnog priznanja učenicima za njihova postignuća, dok uvažavanje učenikove ličnosti obuhvata identifikovanje njegovih autentičnih potreba i uvažavanje prava na različitost. Na drugom mestu, po njihovom mišljenju, nalaze se podsticajne nastavne aktivnosti, koje obuhvataju različite metode rada i kreativne pristupe organizaciji same nastave, kao što su: 
problemske situacije, učenje putem otkrića, istraživački rad i učenje kroz igru. Treće mesto zauzimaju vannastavne aktivnosti, kao što su: sekcije, dodatna nastava, takmičenja, radionice, školske tribine i drugo. Sopstveni profesionalni razvoj nastavnici vide kao veoma bitnu stavku za podsticanje kreativnosti učenika, što ukazuje na to da veoma jasno prepoznaju važnost svoje uloge u tom procesu. Prvenstveno ističu da nastavnici moraju biti model deci sa kojom rade, tj. da treba da se potrude da u odeljenju stvore podsticajnu klimu za razvoj kreativnosti učenika. Nastavnici se zalažu za uspostavljanje sistema za upravljanje kreativnošću koji treba da omogući prepoznavanje i otkrivanje kreativnih potencijala učenika, zatim njihovo usmeravanje, praćenje i pružanje dalje pomoći u okviru profesionalne orijentacije. Ovim zadacima bi trebalo da se bavi tim, u čijem sastavu se nalaze nastavnici, pedagoško-psihološka služba i drugi učesnici vaspitnoobrazovnog procesa. Svakako, neophodne su promene nastavnog programa, koji su nastavnici okarakterisali kao neadekvatan. Oni predlažu da se promene izvrše u domenu sadržaja i organizacije nastave. Naime, smanjivanjem obima nastavnih programa fokus se pomera sa usvajanja informacija ka sticanju funkcionalnih znanja i veština. Smanjivanje broja učenika u odeljenju bi, takođe, doprinelo stvaranju većeg prostora za primenu kreativnih nastavnih metoda.

\subsubsection{Kreativno tumačenje narodnih epskih pesama u nastavi Srpskog jezika i književnosti}

Autorka Snežana Laketa dala je primer savremenog pristupa interpretaciji narodne epske pesme Marko Kraljević i beg Kostadin, uz upotrebu multimedijalne skice (mape uma). U uvodnom delu časa predviđa se gledanje video-snimka o narodnim junačkim pesmama, nakon čega sledi razgovor sa učenicima o njihovim utiscima. Glavni deo časa započinje interpretativnim čitanjem pesme, te podelom učenika u grupe prema pesničkim slikama, svaka grupa dobija zadatak da uz pomoć Rječnika Vuka Stefanovića Karadžića objasni podvučene, nepoznate reči. Sledeći korak je izveštavanje grupa, uz detaljniju sadržajnu i moralnu analizu epske pesme, odnosno razgovor o pesmi uz postepeno formiranje pojedinih delova multimedijalne skice. Završni deo časa obuhvata evaluaciju rezultata rada uz primenu elektronskog testa, nakon čega sledi usmena evaluacija, vođena sledećim pitanjima: „Objasnite koji lik u ovoj pesmi nije dobro postupio? Zašto?” i „Da li ste u još nekim delima pronašli slične primere?”. Za domaći zadatak učenicima je zadato da nauče stihove napamet kako bi podelili uloge za dramatizaciju epske narodne pesme. Takođe, u cilju podsticanja kreativnosti učenika, dat je zadatak da ilustruju epsku pesmu u vidu stripa (Laketa 2016a: 61-62). Prilikom intrepretacije 
epske narodne pesme, u pripremnoj fazi, učenike može motivisati aktivnost istraživanja istorijskih događaja i ličnosti, kroz razne izvore: istorijske udžbenike, enciklopedije, televizijske emisije, pretraga onlajn baza podataka putem interneta. Prilikom tumačenja narodnih epskih pesama od učenika se očekuje da posmatraju probleme na drugačiji način, sa izraženom sposobnošću tolerisanja nejasnoća u konfliktnim reakcijama pojedinih epskih junaka. Tumačenjem epskih pesama kod učenika se razvija sposobnost preuzimanja određenog rizika u pojedinim ključnim momentima života, što je jedna od odlika kreativne ličnosti (Laketa 2016b: 140).

Za mlađe uzraste, autorka predlaže čitanje pesama Zmija mladoženja i Marko Kraljević $i$ vila, koje sadrže elemente bajkovitosti. Učenici petih razreda mogu čitati i analizirati pesme, kao što su: Car Duklijan i Krstitelj Jovan, Bog nikome dužan ne ostaje i Braća i sestre. Razvijanje divergentnog mišljenja kod učenika se može ostvariti postavljanjem niza zagonetki i problemskih pitanja prilikom obrade narodnih epskih pesama. Tako, pesma Marko Kraljević i Musa Kesedžija nudi široki dijapazon mogućnosti za ovakva pitanja: „Je li vam žao Muse u pesmi Marko Kraljević i Musa Kesedžija? Kako ga je Marko pobedio? Je li Marku žao što je pogubio svog protivnika?”. Mogući su (i očekivani) raznovrsni odgovori, prednost narodnih epskih pesama jeste upravo u tome što svi odgovori mogu biti pravi, vodeći dečju maštu u svečane dvorove, na tajanstvene planine, $u$ gore gde stanuju vile i zmajevi, upućuju se uz svatove u tuđe, daleke i nepoznate zemlje što ih često dovede i do megdana, mesta gde se junaci bore (Laketa 2016c: 128).

\subsubsection{Podsticanje kreativnosti putem savremenog pristupa podučavanja muzičke kulture}

Autorka Tihana Škojo (2013: 304) dala je primer savremenog pristupa podučavanja muzičke kulture sa ciljem podsticanja kreativnosti u radu sa učenicima. Reč je o sinhroničnom modelu, konceptu otvorene nastave. Ovaj model postavlja muziku u prvi plan, njegov sadržaj nije moguće unapred utvrditi u obliku raspoređivanja tematskih jedinica po godišnjem rasporedu nastavnih časova. Naime, svaka nastavna jedinica obrađuje se onda kada se steknu uslovi da njena obrada ostvari najbolje rezultate. Na ovaj način se podstiče motivacija učenika za usvajanje novih znanja, veći interes za sve oblike muzičke kulture, izraženija kreativnost $u$ interpretaciji stečenih znanja i njihovoj primeni. Ispitujući mišljenje učenika o kreativnim aktivnostima u nastavi umetničkog područja (likovna i muzička kultura), autorka je došla do sledećih saznanja o mogućim načinima iskazivanja kreativnosti u nastavi: izrada referata, plakata, projekata i crteža, crtanje mapa uma, slušanje i 
prezentovanje muzičkih primera i prepoznavanje likovnih dela, pevanje, plesanje, igranje, posećivanje muzeja i koncerata, razrada tema koje učenici vole, aktivno učestvovanje u nastavi, povezivanje gradiva sa drugim predmetima ili vannastavnim aktivnostima, grafičkim prikazima gradiva.

\subsubsection{Metode i tehnike podsticanja kreativnosti-značaj igre}

Rezultati relevantnih istraživanja pokazali su da učitelji i nastavnici kao najčešće strategije za podsticanje kreativnosti u nastavi izdvajaju sledeće: rad u grupama, slobodno vreme, aktivnosti sa otvorenim krajem, kreativno pisanje, crtanje, oluja ideja, nestrukturisano vreme, kao i određene vrste nastave: problemska, projektna i istraživačka nastava (Fleith 2000; Vrsaljko i Ivon 2009, prema: Kunac 2015: 441). Uslovi za ispoljavanje i razvoj kreativnosti višestruko su povezani sa metodama i tehnikama koje se koriste za podsticanje kreativnosti i stvaralaštva. Prema mišljenju nastavnika, najefektivnije su one metode koje omogućavaju aktiviranje učenika u najvećoj meri, kao što su: rad u paru i učenikovo samostalno dolaženje do odgovora pomoću učenja putem otkrića, istraživanja $\mathrm{i} / \mathrm{ili}$ rešavanja problema. Tako se, metode za obrazovanje kreativnosti zapravo odnose na aktivnosti divergentnog mišljenja, kreativnog rešavanja problema i na aktivnost zvanu „moždana oluja” (Maksimović i Stančić 2012: 74).

De Bono (De Bono 1985, prema: Maksić 2006: 151) je razvio brojne tehnike kreativnog rešavanja problema, a jednu od njih je nazvao „Šest mislećih šešira“. Zapravo, na duhovit način, ovih šest mislećih šešira podsećaju mislioca da tokom celog procesa rešavanja problema odgovara na šest bitnih aspekata. Beli šešir podrazumeva neutralne činjenice, informacije i brojeve. Crveni pokriva osećanja, intuiciju i slutnje. Dalje, crni šešir je zadužen za logiku, nazvanu negativnom jer je to ona koja daje primedbe. Sa druge strane postoji i pozitivna logika, koja ističe šta je dobro u rešenju, ona se nalazi ispod žutog šešira. Zeleni šešir je zadužen za kreativnost, za ono što je novo. I poslednji, šesti, šešir plave boje sadrži misli koje se odnose na kontrolu mišljenja. Na času, učenici individualno, jedan po jedan, ili u grupi, mogu da rešavaju, na primer, samo jedan aspekt problema i otkriju šta je u jednom od šešira.

Brojne su mogućnosti primene igara u nastavnim aktivnostima, prvenstveno u mlađim razredima osnovne škole. Igra, kao stvaralačka aktivnost sama po sebi, pruža deci mogućnost da slobodno manipulišu predmetima, koristeći uz to prethodno stečena iskustva. Igra podstiče intrizičnu motivaciju kod deteta, jača samokontrolu, usmerava njegovu pažnju i ponašanje. U nastavi Srpskog jezika i književnosti i Matematike učitelji organizuju didaktičke igre rečima i stonim štampanim 
materijalima. Kroz nastavu ostalih predmeta organizuju se igre zvucima, gestovima, pokretom, igre dramatizacije i različite konstruktorske aktivnosti. Za razvoj kreativnih potencijala učenicima se nude kulturni i umetnički materijali: za crtanje, oblikovanje, sviranje, pevanje i igranje. Ove materijale je moguće razvrstati prema nivoima težine i složenosti, pri čemu treba voditi računa da deca na ovom uzrastu rešavaju zadatke krećući se od jednostavnijih ka složenijim, od konkretnijih ka apstraktnijim (Danilović 2003, prema: Kopas-Vukašinović 2006: 180). Sa psihološkog aspekta, dečja simbolička igra se posmatra kao rana manifestacija stvaralačkih sposobnosti, te se zbog toga teži ka što češćoj primeni u nastavi. U okviru nastave Srpskog jezika i književnosti primenjuje se dramski metod kao vid podsticanja kreativnosti i stvaralaštva učenika. Naime, dramatizacija kao oblik stvaralaštva odgovara pokretnoj prirodi dečje mašte i predstavlja najčešći oblik dečjeg stvaralaštva. Dramski metod je oblik učenja kroz igru, metod realizacije nastavnih sadržaja iniciranjem stvaralačkog dijaloga. Kratke dramske improvizacije, koje se koriste u nastavi, zasnivaju se na konkretnoj priči, ili problemskoj situaciji, sa kojom se učenici do tada nisu susretali, a čije rešavanje zahteva preduzimanje odgovarajućih uloga, kao i veštinu da se stečeno znanje kritički i aktivno primeni. Dramski metod jača dečje komunikativne sposobnosti, kao i njihovo samopouzdanje. Samopouzdanje zauzima značajno mesto u strukturi kreativne ličnosti, jer nedostatak istog automatski inhibira stvaralački zamah učenika (Stevanović i Dimitrijević 2013: 396-397).

Postoje i primeri kako se igra može koristiti i u nastavi Sveta oko nas. Naime, aktivnosti se organizuju u okviru programa „Ekologijom za sadašnji i budući život ove planete". Predviđene su za decu mlađeg osnovnoškolskog uzrasta. Uvodna aktivnost realizuje se kroz igru To je ekologija, kroz koju deca treba da usvoje osnovne pojmove iz ove oblasti. Zatim, sledi igra Pričam ti priču, koja se oslanja na stečena znanja iz prethodne aktivnosti. Kombinacijom igre pokretom i igre mašte ili uloga, ova igra ostvaruje svoj cilj - deca shvataju značaj uticaja čoveka na prirodnu sredinu i zapažaju koje se sve promene dešavaju u prirodi, prouzrokovane pozitivnim ili negativnim ljudskim delovanjem. Sledeća aktivnosti jeste igra uloge Asertivno kroz ekologiju, koja ima za cilj razvijanje sposobnosti samopouzdanog reagovanja dece, formiranja navika kulturnog ponašanja, kao i jedinstvenog delovanja prema prirodi. Igrom Signali iz prirode nastoji se pružiti pomoć deci u shvatanju ponašanja određenih životinja u prirodi, kroz igru imitacije ili pantomime. Ovaj program obuhvata i druge brojne aktivnosti, odnosno igre, kao što su: Smešni kipovi, Prirodne čarolije, Šumske životinje, i druge (Kopas-Vukašinović 2006: 184). 
3.4. Mogućnosti podsticanja kreativnosti kroz vannastavne i vanškolske aktivnosti i kako ih iskoristiti u nastavnom procesu - primeri dobre prakse

Jedna od važnijih funkcija savremene škole je pružanje mogućnosti učenicima da se angažuju u vannastavnim aktivnostima. $U$ toku ovih aktivnosti učenici imaju mogućnosti da maksimalno izražavaju svoju slobodu i stvaralačke uloge (Zrilić i Košta 2009: 160). Vannastavne aktivnosti odvijaju se u školi pod manjim pritiskom obaveznog i unapred određenog plana, te mogu da pruže povoljnije uslove za razvoj kreativnog izražavanja učenika. U ovu kategoriju aktivnosti ubrajaju se razne sekcije koje učenici mogu da pohađaju, kao i aktivnosti u produženom boravaku, sa ciljem da se vreme što kvalitetnije iskoristi za podsticanje njihove kreativnosti. Kao jedan od primera pružanja podrške kreativnosti učenika izvan redovne nastave i obaveznih školskih aktivnosti, autorka Maksić navodi rad Međunarodnog centra za radoznalu decu iz Londona. Programi su namenjeni deci uzrasta od tri do deset godina. Ovaj Centar ima za cilj pronalaženje načina za „otključavanje” potencijala svakog deteta, kako bi vodili ispunjen i kreativan život. Rad Centra se odvija u okviru programa koji su podeljeni u dve grupe. Prva se odnosi na decu uzrasta od tri do pet godina, čiji roditelji veruju da njihova deca imaju određene talente i da mogu imati korist od ovakvog obrazovanja. Druga grupa obuhvata decu od pet do deset godina koja vole da uče i koja će imati koristi od obogaćujućeg programa, namenjenog razvijanju dečjih talenata. Grupe imaju časove dva puta nedeljno, jedan čas traje 30 minuta, a ukupno imaju 9 časova na nedeljnom nivou. Programi se organizuju za sledeće predmete: francuski i nemački jezik kao strani jezici, engleski kao maternji, umetnost, prirodne nauke, logika, filozofija, korišćenje kompjutera, ritam života i kaleidoskop, koji obuhvata kolaž kojim se deci predstavljaju neobični ljudi i njihova zanimanja. U literaturi je opisan primer obogaćujućeg i diferenciranog radnog lista za obradu teme Prodavnica. Prvi zadatak koji se postavlja pred decu jeste da naprave listu svih prodavnica koje poznaju, abecednim redosledom. Zatim se od njih traži da zamisle da otvaraju svoju prodavnicu, te da odluče koja je to prodavnica, gde će se nalaziti, kakva će biti njena unutrašnjost, da isplaniraju kako bi izgledao dan velikog otvaranja njihove prodavnice. Sledeći zadatak je da nacrtaju sliku ulaznog dela prodavnice, zatim, da napišu dnevnik na kraju prvog radnog dana. Sledeći zadatak je da napišu oglas za pomoćnika, s obzirom na to da ne mogu sami voditi prodavnicu, da se na taj isti oglas prijave u ulozi radnika. Od njih se očekuje da napišu sastav u kojem će opisati dobrog prodavca. Za izradu ovog sastava mogu pitati i druge osobe za njihova mišljenja. Nakon toga, imaju zadatak da napišu sastav na temu „O lopovima koji kradu po prodavnicima". Pretposlednji zadatak ih navodi da zamisle da je njihov 
prijatelj kupio cipele koje su se pocepale posle dva dana, neophodno je da sa njim napišu reklamaciju, koristeću prospekt za istu. Konačno, poslednji zadatak u okviru ove teme se odnosi na ,tragediju”. Naime, deci je rečeno da zamisle da su ih vatrogasci probudili i rekli im da je njihova prodavnica izgorela. Traži se od njih da napišu kako se osećaju u tom trenutku, sa što bogatijim i punijim opisom. Cilj opisanih aktivnosti jeste da deci pruži mogućnost da ispituju nepoznato i da imaju slobodu izbora (Maksić 2006: 175-180).

Kako bi privukli što veći broj korisnika, a biblioteke postale interesantno mesto za populaciju kojima dolazak u ove ustanove kulture nije navika, većina odeljenja javnih biblioteka je u stalnom traganju za novim sadržajima, kao i idejnim rešenjima, u pristupu kojim se deca i mladi uvode u svet pisane reči. Polazeći od shvatanja da razvoj pojedinca ne može biti celovit ako ne sadrži stvaralaštvo i kreativnost kao komponentu ukupnog razvoja, u Dečjem odeljenju Biblioteke grada Beograda organizovani su brojni edukativni i kreativni programi, kao što su: Susret sa piscem, Vrtić u biblioteci, Koncert u biblioteci, Ekološka radionica, Radionica kreativnog stvaralaštva, Zaroni u priču i slično. Danas razvoj informacionokomunikacionih tehnologija otvara široko polje delovanja u nastojanjima pronalaženja novih načina na koje bi nove tehnologije delovale u službi podsticanja stvaralaštva i kreativnosti. Tako su razvijeni kvalitetni i kreativni kompjuterski programi, sa velikim obrazovnim potencijalom, koji u interakciji sa kompjuterskim igricama mogu biti od znatne koristi u radu sa decom osnovnoškolskog i srednjoškolskog uzrasta. Reč je o sledećim programima: Comic Life, namenjen pravljenju stripa, Inkle Writer za pisanje priča, kao i PowerPoint sa akcentom na alatki hiperlink, podesnoj za kreiranje priča sa više tokova i završetaka, poznatom pod nazivom ,izaberi svoju pustolovinu”. Bibliotekari Dečjeg odeljenja Biblioteke grada Beograda organizovali su ciklus edukativno-zabavnih radionica, koje omogućavaju učenicima osnovnoškolskog uzrasta da koriste omiljene likove iz kompjuterskih igara, i da uz pomoć programa Comic Life naprave svoje stripove i preporuke za čitanje. Ovaj kompjuterski program je odličan izbor za pisanje dijaloga, za predstavljanje ključnih informacija, jer angažuje korisnike kroz razmišljanje, stvaranje i pisanje, te podstiče kreativnost i više misaone procese. Učenicima se, uz pomoć ovog programa, otkriva kako omiljena književna dela mogu predstaviti drugima, jer će ih prepričati u nekoliko rečenica i pomoću elemenata koje nude kompjuterske igre napraviti strip-preporuku za čitanje. $\mathrm{Na}$ ovaj način deci, roditeljima i svima ostalima se pokazuje da kompjuteri i kompjuterske igre, sa jedne strane, i kreativnost i stvaralaštvo, sa druge, ne moraju da budu predstavljeni kao međusobno suprotstavljene kategorije, već kao drugo lice istog procesa, odnosno podsticanja celokupnog razvoja individue (Đorđević, V. 2014: 26-29). 
Na kraju, kada je reč o podsticanju kreativnosti kroz vanškolske aktivnosti, treba predstaviti postupke za podsticanje dečjeg stvaralaštva, kako bi se taj proces odvijao na što kvalitetniji način. Reč je o sledećim postupcima:

- postupci za proširivanje obima dečjeg fizičkog, socijalnog i logičkomatematičkog iskustva, kao i njegovo podizanje na razvojno viši nivo;

- postupci za unapređivanje radoznalosti, sklonosti ka postavljanju pitanja, traganjem za nepoznatim, da se misli na neuobičajen način i da se isprobavaju nova rešenja, koja nisu naučena od drugih;

- postupci za usavršavanje komunikacije;

- uzdržavanje od svih postupaka kojima se detetu propisuju određene radnje, kao što je kopiranje modela, ili objašnjenje kako nešto da uradi, jer se na taj način sputava njegova kreativnost;

- vođenje računa da novi motivi i funkcije bavljenja stvaralačkim istraživanjem ne potisnu ono što je izgrađeno na prethodnim stadijumima razvoja, što se prvenstveno odnosi na motivaciju i zadovoljstvo koji proizilaze iz igre, ali i na spontanost, iskrenost i svežinu izraza;

- dečje stvaralačko izražavanje treba da zadrži svojstvo igre tokom predškolskog i mlađeg školskog uzrasta, jer je igra ta koja privlači i motiviše dete na aktivnost i učenje (Kulić i sar. 2008: 227-228).

\section{ZAKLJUČAK}

O nesumnjivom značaju kreativnosti i stvaralaštva za holistički razvoj ličnosti pisali su brojni autori, sa različitih aspekata. S obzirom na to, postavlja se pitanje zašto i dalje u našem društvu ne postoji dovoljno napora i podsticaja usmerenih ka razvoju kreativnih potencijala dece i mladih? Ovo i slična pitanja dovela su do potrebe za proučavanjem mogućih načina podsticanja kreativnosti.

$\mathrm{Na}$ osnovu proučavane literature izvodi se zaključak da se podsticanje kreativnosti može vršiti na tri nivoa: na nivou učionice, obrazovnog sistema i društva. Na nivou učionice kreativnost se može podsticati kroz različite nastavne $\mathrm{i}$ vannastavne aktivnosti, kao i kroz razvoj podsticajne školske klime. Dalje, na nivou obrazovnog sistema podsticanje kreativnosti zahteva promene u okviru nastavnog programa, profesionalnog razvoja nastavnika i kroz razvijanje sistema za upravljanje kreativnošću. Na nivou društva potrebno je razviti svest građana o većem vrednovanju kreativnosti (Bodroža, Maksić i Pavlović 2013: 111). 
Ukoliko smo svesni značaja ovih procesa za razvoj ličnosti, a znamo i načine za njihovo podsticanje, zašto to onda ne činimo? Čini se da je veoma teško napraviti jedinstven model podsticanja kreativnosti u nastavnom procesu, koji bi bio primenljiv u svim školama, učionicama i u radu sa svim učenicima. Zapravo, to je nemoguće iz nekoliko razloga. Prvenstveno, svaka škola ima svoje specifične karakteristike s obzirom na svoje osobenosti i osobenosti svog društvenog okruženja. Dalje, u svakom razredu, pa i u odeljenju, nalaze se učenici sa različitim željama i mogućnostima, kao i učitelji i nastavnici koji imaju lični stil poučavanja, način komunikacije i saradnje sa učenicima, pri čemu primenjuju različite metode i oblike rada. Ono što je moguće, ostvarivo i poželjno jeste implementacija različitih teorija podsticanja kreativnosti u nastavnom procesu, shodno karakteristikama društva, škole, nastavnog osoblja i najbitnije, karakteristikama i mogućnostima samih učenika. Da bi se navedeno ostvarilo, neophodno je koncipirati kurikulum tako da učiteljima i nastavnicima ostavlja prostor, vreme i materijale za kreativan rad, i ono najvažnije, podsticati učitelje i nastavnike na kontinuirano usavršavanje o načinima i mogućnostima podsticanja kreativnosti u nastavnom procesu (Koludrović i ReićErcegovac 2010: 428-429).

Navedeno pokazuje da mogućnosti postoje, da postoje i napori da se u ovoj oblasti napreduje, ali da je to kontinuiran proces, da su potrebna stalna usavršavanja i inoviranja, kako bi se išlo u korak sa promenama, u korak sa razvojem pojedinca, koji postaje sve brži u savremenim uslovima života. Zato je potrebno da i akteri uključeni u ovaj proces razvijaju svoju kreativnost, kreativne metode i tehnike, jer kao i svako vaspitno delovanje, tako i ovo, najbolje efekte daje ukoliko postoji pozitivan lični primer. Deci i mladima treba dati slobodu, pružiti im široke mogućnosti da razmišljaju, stvaraju i kreiraju, bez pritisaka i ograničenja koja su sastavni deo naše svakodnevnice. Potrebno je da svi deluju zajedno, da zajedničkim naporima teže da stvore okruženje koje će deci i mladima omogućiti razvoj svestrane ličnosti, što nije moguće ukoliko se zanemare ili sputavaju njihovi kreativni potencijali. Škola sadašnjosti treba da pomaže svojim kreativnim učenicima kako bi svi zajedno radili na izgrađivanju škole budućnosti.

\section{LITERATURA}

Bačlija-Sušić, B., Sućeska-Ligutić, R. (2017). „Poticanje kreativnih sposobnosti učenika glazbenih škola”. Metodički ogledi 24(1): 73-94.

Balažević, E. (2010). „Kreativnost u nastavi”. Život i škola 23(1): 181-184.

Bognar, L. (2012). „Kreativnost u nastavi”. Napredak 153(1): 9-20. 
Бодрожа, Б., Максић, С., Павловић, Ј. (2013). „Испољавање и подстицање креативности у основној школи из перспективе наставника". Зборник Института за педагошка истраживања 45(1): 108-130 [Bodroža, B., Maksić, S., Pavlović, J. (2013). „Ispoljavanje i podsticanje kreativnosti u osnovnoj školi iz perspektive nastavnika“. Zbornik Instituta za pedagoška istraživanja 45(1): 108-130].

Dubovicki, S. (2012). „Poticanje kreativnosti u udžbenicima razredne nastave”. Pedagogijska istraživanja 9(1-2): 205-221.

Ђорђевић, J. (2014). „Креативност - подстицаји и неговања”, у Даровитост и креативност - развојна перспектива креативне перформансе, ур. Г. Гојков и С. Пртљага (Вршац: Висока школа струковних студија за васпитаче „Михаило Павлов”): 43-44 [Đorđević, J. (2014). „Kreativnost podsticaji i negovanja“, u Darovitost i kreativnost - razvojna perspektiva kreativne performanse, ur. G. Gojkov i S. Prtljaga (Vršac: Visoka škola strukovnih studija za vaspitače „Mihailo Pavlov”): 43-44].

Ђорђевић, В. (2014). „Компјутерске игре у служби подстицања креативности и стваралаштва код деце”. Глас библиотеке 20: 23-32 [Đorđević, V. (2014). „Kompjuterske igre u službi podsticanja kreativnosti i stvaralaštva kod dece". Glas biblioteke 20: 23-32].

Fudurić, B. (2012). „Mogućnosti rada u izvannastavnoj aktivnosti”. Napredak 153(1): 107-116.

Jukić, R. (2010). „Metodički stil i takt nastavnika kao poticaj kreativnosti učenika”. Pedagogijska istraživanja 7(2): 291-305.

Koludrović, M., Reić-Ercegovac, I. (2010). „Poticanje učenika na kreativno mišljenje u savremenoj nastavi”. Odgojne znanosti 12(2): 427-439.

Копас-Вукашиновић, Е. (2006). „Улога игре у развоју деце предшколског и млађег школског узраста". Зборник Института за педагошка истраживања 38(1): 174-189 [Kopas-Vukašinović, E. (2006). „Uloga igre u razvoju dece predškolskog i mlađeg školskog uzrasta”. Zbornik Instituta za pedagoška istraživanja 38(1): 174-189].

Kulić, B. i sar. (2008). Oseti umetnost: interkulturalno iskustvo u muzejskoj edukaciji. Novi Sad: Galerija Matice srpske.

Kunac, S. (2015). „Kreativnost i pedagogija”. Napredak 156(4): 423-446.

Laketa, S. (2015). „Efekat savremene interpretacije narodnih epskih pesama na uspešnost tumačenja narodnih poslovica”. Obrazovna tehnologija 4: 325342.

Laketa, S. (2016a). „Savremeni pristup interpretaciji narodne epske pesme Marko Kraljević i beg Konstadin". Obrazovna tehnologija 1: 57-66. 
Лакета, С. (2016б). „Анализа експерименталних ефеката увођења иновативних модела у настави српског језика и књижевности”. Годишъак Српске академије образовања 12: 137-146 [Laketa, S. (2016b). „Analiza eksperimentalnih efekata uvođenja inovativnih modela u nastavi srpskog jezika i književnosti”. Godišnjak Srpske akademije obrazovanja 12: 137146].

Laketa, S. (2016c). „Utjecaj suvremenog pristupa u tumačenju epske pjesme na kreativnost učenika”. Metodički ogledi 23(2): 121-139.

Majl, A. (1968). Kreativnost u nastavi. Sarajevo: Svjetlost.

Maksimović, A., Stančić, M. (2012). „Nastavne metode iz perspektive nastavnika”. Metodički obzori 7(1): 69-82.

Максић, С., Ђуришић-Бојановић, М. (2003). „Мерење креативности деце помоћу тестова". Зборник Института за педагошка истражсивања 36: 85-105 [Maksić, S., Đurišić-Bojanović, M. (2003). „Merenje kreativnosti dece pomoću testova". Zbornik Instituta za pedagoška istraživanja 36: 85105].

Maksić, S. (2006). Podsticanje kreativnosti u školi. Beograd: Institut za pedagoška istraživanja.

Maksić, S. (2015). „Darovitost, talenti i kreativnost: od merenja do implicitnih teorija", u O kreativnosti i umetnosti - savremena psihološka istraživanja, ur. B. Dimitrijević (Niš: Izdavački centar Filozofskog fakulteta): 11-27.

Ninčević, M., Jurić, D. (2016). „Uloga kompetencije kreativnosti i socijalne kompetencije u nastavi vjeronauka”. Obnovljeni život 71(2): 247-257.

Pavlović, J., Maksić, S. (2014). „Implicitne teorije kreativnosti nastavnika osnovne škole: studija slučaja". Psihologija 47(4): 465-483.

Perić, B. (2013). „Kreativnost u nastavi”. Teorijski i praktični problemi i rasprave: $145-151$.

Portner-Pavićević, J., Večei-Funda, V., Janjušić, D. (2014). „Kreativnost - između mitova i istine", u Darovitost $i$ kreativnost - razvojna perspektiva kreativne performanse, ur. G. Gojkov i S. Prtljaga (Vršac: Visoka škola strukovnih studija za vaspitače „Mihailo Pavlov”): 79-80.

Simel, S., Gazibara, S. (2013). „Kreativnost u nastavi hrvatskoga jezika”. Život $i$ škola 29(1): 188-204.

Somolanji, I., Bognar, L. (2008). „Kreativnost u osnovnoškolskim uvjetima”. Život $i$ škola 19: 87-94.

Stevanović, M. (2003). Modeli kreativne nastave. Rijeka: Andromeda.

Стевановић, Ј., Димитријевић, М. (2013). „Подстицање иницијативе, сарадње и стваралаштва у настави српског језика и књижевности". Зборник 
Института за педагошка истраживања 45(2): 381-403 [Stevanović, J., Dimitrijević, M. (2013). „Podsticanje inicijative, saradnje i stvaralaštva u nastavi srpskog jezika i književnosti”. Zbornik Instituta za pedagoška istraživanja 45(2): 381-403].

Škojo, T. (2013). „Kreativnost učenika srednjih škola u nastavi umjetničkoga područja”. Život $i$ škola vol. 59, br. 29(1): 300-316.

Zrilić, S. \& Košta, T. (2009). „Učitelj - kreator izvannastavnih aktivnosti”. Magistra ladertina 4(1): 159-170.

Zuliani, Đ., Matić, M., Keteleš, V. (2012). „Poticanje kreativnosti u nastavi informatike". Teorijski i praktični problemi i rasprave: 25-37.

Lana Tomčić

University of Novi Sad

Faculty of Philosophy, Department of pedagogy

POSSIBILITIES FOR ENCOURAGING STUDENTS' CREATIVITY

\section{Summary}

Starting from the fact that creativity is an important part of overall personality, the aim of this paper is to review possible forms of encouraging it in work with students. The goal is achieved using the method of theoretical analysis and the content analysis technique. The paper starts with various definition of creativity and a closer determination of the characteristics of creative individuals. The second part deals with the consideration of the role of teachers in the process of developing creativity through the following questions: is a creative teacher a prerequisite for the development of students creativity, and are we encouraging or reducing creativity in teaching process? The study leads us to the conclusion that it is necessary for a teacher to be creative and the most frequent factors which hinder the development of creativity in teaching are rigid methods and forms of work, disregard of students' individuality, innovativeness, creative thinking and original solutions to problem situations. The results of the analysis of the findings of relevant research and the study literature refer to a number of elaborated strategies in the context of the teaching process and extracurricular activities presented in the paper, such as: ten models of creative teaching, examples of creative processing of epic poems, contemporary teaching of music culture, creative solving of the problem of "Six thinking hats", the use of games as a means of encouraging creativity in working with younger students, group work, creative writing, drawing, brainstorming, and mind maps. Also, the use of programmes such as Comic Life, Inkle Writer and PowerPoint has been presented in the process of content processing in order to encourage creativity. In the concluding observations pedagogical implications of the study of the given problem are presented.

Key words: encouragement, creativity, teacher, teaching, students.

Primljeno: 10. 5. 2019.

Prihvaćeno: 29. 7. 2019. 